\title{
Emoções positivas no uso do espaço construído de um campus universitário associadas aos atributos do design biofílico
}

Positive emotions in the use of the built space associated with the attributes of biophilic design

\section{Flora Bittencourt Detanico \\ Felipe André Schwab \\ Gabriela Zubaran de Azevedo Pizzato \\ Fabio Gonçalves Teixeira \\ $J$ ocelise J acques de J acques \\ Branca Freitas de Oliveira}

${ }^{1}$ Flora Bittencourt Detanico

${ }^{1}$ Universidade Federal do Rio Grande do Porto Alegre - RS - Brasil https:// orcid. org/ 0000-0003-3694-9069

${ }^{2}$ Felipe André Schwab ${ }^{2}$ Universidade Federal do Rio Grande do Porto Alegre - RS - Brasil

${ }^{3}$ Gabriela Zubaran de Azevedo Pizzato ${ }^{3}$ Universidade Federal do Rio Grande do Porto Alegre - RS - Brasil

${ }^{4}$ Fabio Gonçalves Teixeira ${ }^{4}$ Universidade Federal do Rio Grande do Porto Alegre - RS - Brasil

$5 \mathrm{~J}$ ocelise $\mathrm{J}$ acques de $\mathrm{J}$ acques 5Universidade Federal do Rio Grande do Porto Alegre - RS - Brasil

${ }^{6}$ Branca Freitas de Oliveira ${ }^{6}$ Universidade Federal do Rio Grande do Porto Alegre - RS - Brasil

Recebido em 05/09/18 Aceito em 14/01/19

\section{Resumo}

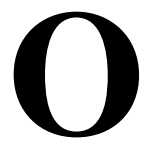

design biofílico proporciona soluções de integração da natureza com os ambientes construídos, promovendo agradabilidade (pleasantness) e bem-estar para os usuários. Este trabalho tem como objetivo identificar emoções positivas dos usuários, associadas aos atributos do design biofílico na avaliação do ambiente construído do novo campus Unisinos, em Porto Alegre. O método proposto abrange uma etapa qualitativa e outra quantitativa, partindo da pesquisa de satisfação com os usuários. Por meio da estruturação de questionário, são aferidas maiores informações a respeito das emoções positivas elicitadas pelos atributos da edificação, assim como da intensidade em que essas emoções são percebidas pelos alunos na interação com o espaço. Os resultados demonstram a contribuição positiva do campo de estudo do design e emoção, bem como do design biofílico, para avaliação do ambiente construído.

Palavras-chave: Design biofílico. Design e emoção. Avaliação do ambiente construído.

\section{Abstract}

Biophilic design has brought nature integration solutions with built-in environments, promoting pleasantness and well-being for users. This paper aims to identify users' positive emotions associated to the attributes of biophilic design in the evaluation of the built environment of the new Unisinos campus, in Porto Alegre. The proposed method includes a qualitative and a quantitative step, starting with satisfaction survey with the users. A questionnaire was developed to gain more information about the positive emotions elicited by the attributes of the building and the intensity by which those attributes are perceived by the students in interaction with the space. The results demonstrate the positive contribution of the study of design and emotion, as well as biophilic design, to evaluate the built environment.

Keywords: Biophilic design. Design and emotion. Built environment evaluation. 


\section{Introdução}

A crescente urbanização do mundo contemporâneo resulta em cidades caracterizadas por densas áreas construídas e cada vez menos espaços em contato direto com a natureza. O relatório de Browning e Cooper (2017) destaca o Brasil como um dos países com maior índice de crescimento urbano, mensurado de 1950 a 2010, em 51\%. Esse aumento acelerado da urbanização tem despertado maior interesse pela biofilia, campo de estudo que descreve a relação inata entre o homem e a natureza, além de tratar da necessidade do indivíduo em permanecer conectado a ela (WILSON, 1984).

O design biofílico é uma teoria, uma ciência e uma prática, que visa a criação de ambientes inspirados na natureza, buscando ampliar a conexão do indivíduo com ela, nos espaços em que mora e trabalha. Nesse contexto, os locais de trabalho têm especial importância, em função das longas horas de permanência em estado de atenção (BROWING; COOPER, 2017). O extenso relatório, realizado pelos mesmos autores, aborda as necessidades do ser humano e os potenciais biofílicos dos espaços de trabalho. Os dados obtidos indicam que pessoas que trabalham em escritórios contendo elementos naturais, como plantas e luz natural, são $15 \%$ mais criativos, 6\% mais produtivos e apresentam 15\% mais bem-estar.

O ambiente construído atua diretamente nas percepções de uso do espaço, provocando emoções positivas ou negativas, as quais modificam o significado das experiências (NASSAR, 1994). Os atributos das edificações e seu contexto urbano desempenham importante papel no uso do espaço e no comportamento de seus usuários (MOURTHE, 1998; REIS; LAY, 2005, 2006; JOHN; REIS, 2010; PIZZATO, 2013). A interação com ambientes agradáveis, por exemplo, pode aumentar a calma e a segurança, reduzindo a agressividade e estimulando o entusiasmo (KÜLLER, 1980). A partir dessa perspectiva, é possível identificar efeitos positivos ou negativos de propostas de projeto, além de sugerir alternativas para minimizar problemas existentes.

O presente trabalho tem como objetivo identificar quais emoções positivas são evocadas no uso do ambiente construído, relacionando-as com os atributos do design biofílico. Para tanto, é necessário compreender as percepções dos usuários ao vivenciarem o espaço construído durante suas experiências de trabalho, estudo e convivência, avaliando quesitos como satisfação, alegria e inspiração. Para o estudo de caso, foram selecionadas as edificações do novo campus da Unisinos - Universidade do Vale do Rio do Sinos em Porto Alegre, as quais oferecem elementos arquitetônicos que oportunizam a interação do usuário com a natureza, seja pela amplitude dos espaços, pela presença de vegetação, vistas panorâmicas, luz natural, entre outros. Os projetistas almejaram a construção de um cenário universitário propício ao estímulo dos diversos usuários em suas experiências de estudo, trabalho e convivência.

\section{Referencial teórico}

Como referencial teórico para a pesquisa, são abordadas duas áreas do conhecimento: o design e emoção, com ênfase nas percepções e emoções positivas experimentadas pelo usuário na interação com o ambiente construído e, por outro lado, os atributos do design biofílico, como diretrizes para projetos mais sustentáveis, propícios e agradáveis ao uso do ser humano.

\section{Emoções positivas no uso do ambiente construído}

O planejamento arquitetônico de uma edificação visa atingir um desempenho ambiental plenamente satisfatório, que responda a diferentes influências. Dentre tais influências, encontram-se condições térmicas (temperatura, vento e umidade), qualidade acústica (proteção de ruídos intrusivos), condições de visão e iluminação (natural ou artificial), poluição, qualidade interna do ar, estabilidade estrutural da edificação, salubridade, higiene, segurança, entre outros (OCHOA; ARAÚJO; SATTLER, 2012).

Monteoliva e Pattini (2013) evidenciam a eficiência do acondicionamento bioclimático e das estratégias de uso da iluminação natural para qualificação das salas de aula em termos de economia de energia, qualificação da saúde, do conforto e satisfação dos usuários. Segundo Valesan, Fedrizzi e Sattler (2010), o uso de vegetação junto aos ambientes construídos gera benefícios notáveis às condições térmicas, amenizando as radiações solares, mediante o sombreamento dos galhos e folhas, controlando a temperatura por meio da transpiração do vegetal. Além disso, o contato com a vegetação proporciona ao usuário bem-estar físico e mental, incentivando a criatividade e redução do estresse (VALESAN; FEDRIZZI; SATTLER, 2010).

Avaliações das reações emocionais dos usuários atreladas ao uso do espaço (NASAR, 1994) são escopo da arquitetura e da percepção ambiental. Espaços, públicos ou não, interferem de forma significativa na felicidade ou infelicidade das pessoas, oferecendo dificuldades ou facilidades, 
como o nível de segurança, de conforto e de agradabilidade estética (SOUZA, 2003). Segundo Russel e Mehrabian (1977), as pessoas se aproximam mais de espaços agradáveis. Além disso, as percepções de felicidade ou agradabilidade, associadas ao sentimento de excitação ou entusiasmo, tornam o espaço ainda mais atrativo.

A emoção, que afeta a forma como as pessoas pensam e se comportam, ganhou significativa atenção no campo do design (KHALID; HELANDER, 2006). Segundo Norman (2008), dependendo de como são configurados, os objetos provocam emoções positivas ou negativas na interação com o usuário, visto que o sistema emocional influencia o funcionamento do sistema cognitivo. Mediante emoções positivas, as pessoas tendem a ser mais criativas, socialmente integradas, saudáveis e resilientes (FREDRICKSON; TUGADE; WAUGH, 2003).

A pesquisa bibliográfica na área do design e emoção contribuiu para uma taxonomia de emoções positivas, a qual pode servir de referência para o desenvolvimento das etapas seguintes do trabalho. $\mathrm{O}$ artigo Faces of Product Pleasure: 25 positive emotions in Human-Product Interations, de Desmet (2012), apresenta 25 emoções positivas, as quais foram traduzidas para o português e estão brevemente explicadas na Figura 1.

Figura 1 - Tipologia geral das 25 emoções positivas

\begin{tabular}{|c|c|c|c|}
\hline (1) & $\begin{array}{l}\text { simpatia } \\
\text { Experimentar um desejo de se identificar com sentimentos de infortúneo de alguém } \\
\text { compaixăo / empatia / piedade } \\
\text { bondade } \\
\text { Experimentar a tendéncia de proteger ou contribuir com o bem estar de alguém } \\
\text { cuidado / amigável / temura / calor }\end{array}$ & 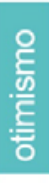 & $\begin{array}{l}\text { esperança } \\
\text { Experimentar a crença ou desejar para que algo bom possivelmente aconteça } \\
\text { otimismo / encorajado / desejoso } \\
\text { antecipação } \\
\text { Aguardar ansiosamente um evento desejável o qual tem expectativa que aconteça } \\
\text { ansioso / expectante }\end{array}$ \\
\hline$\frac{\mathrm{C}}{\mathrm{E}}$ & $\begin{array}{l}\text { respeito } \\
\text { Experimentar a tendéncia a considerar alguém como digno, bom ou valioso } \\
\text { apreciaçăo / aprovaçăo } \\
\text { amor } \\
\text { Experimentar um desejo de ser carnnhoso e cuidar de alguem }\end{array}$ & 㡙 & $\begin{array}{l}\text { Surpresa } \\
\text { Ser agradado por algo que acontece de repente, e que foi inesperado ou incomum } \\
\text { espanto / atônito / assustado / ofuscado } \\
\text { estímulo } \\
\text { Desfrutar de um estado de alto espinto, de ser energizado ou vitalizado } \\
\text { exuberante / entusiasmo / exitaçăo / estimulaçăo }\end{array}$ \\
\hline 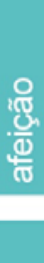 & $\begin{array}{l}\text { afeiçăo / intimidade / romance / paixăo } \\
\text { admiração } \\
\text { Experimentar um desejo de premiar e estimar alguém pelo seu valor ou realizaçăo } \\
\text { impressâo / estima } \\
\text { devaneio } \\
\text { Desfrutar de um estado calmo de introspecçăo e ponderaçăo } \\
\text { pensativo / contemplativo }\end{array}$ & 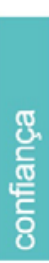 & $\begin{array}{l}\text { Coragem } \\
\text { Experimentar força mental ou moral para perseverar e resistir a perigos ou dificuldades } \\
\text { bravo / animado } \\
\text { Orgulho } \\
\text { Expenmentar um agradável senso de auto-estima ou realizaçăo } \\
\text { tiunfante, auto satisfaçăo / presunçoso } \\
\text { segurança } \\
\text { Expenimentar fé em si mesmo ou em suas habilidades de conquistar ou agir bem } \\
\text { garantia / segurança / confiança }\end{array}$ \\
\hline 密. & $\begin{array}{l}\text { Experimentar um apelo ou apette sexual } \\
\text { paixăo / sensualidade / teş̋o / sexy } \\
\text { desejo } \\
\text { Experimentar uma forte atraçăo para desfintar ou possuir algo } \\
\text { atraçăo / ansiar / almejar } \\
\text { adoração } \\
\text { Experimentar um desejo de idolatrar, honrar, e ser devoto de alguém } \\
\text { adoro / devoçฎ̆o / reverência }\end{array}$ & 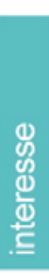 & $\begin{array}{l}\text { inspiração } \\
\text { Experimentar um repentino e forte sentimento de impulso criativo } \\
\text { entusiasmo / determinaçăo / desafiado / fervor } \\
\text { encantamento } \\
\text { Ser cativado por algo que é experimentado como delicioso ou extraordinário } \\
\text { adimiraçăo / encantado / tocado } \\
\text { fascinação } \\
\text { Experimentar um desejo de explorar, investigar ou entender algo } \\
\text { cunoso / atento / interessado / absorto }\end{array}$ \\
\hline 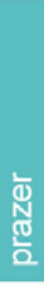 & $\begin{array}{l}\text { euforia } \\
\text { Ser levado por uma experiència irresistivel de alegria intensa } \\
\text { extase / elaçăo / jubilaçăo } \\
\text { alegria } \\
\text { Estar satsfeito (ou ter prazer com) alguém ou algum evento desejado } \\
\text { felicidade / prazer / deleite } \\
\text { diversão } \\
\text { Desfrutar um estado lúdico de humor ou entretenimento } \\
\text { entretenimento / cơmico / alegria }\end{array}$ & 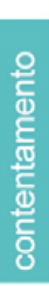 & $\begin{array}{l}\text { alívio } \\
\text { Desfrutar uma recente remoçăo de estresse ou desconforto } \\
\text { tranquilizado / acalmado / gratidăo } \\
\text { relaxamento } \\
\text { Desfrutar de um estado calmo de ser, livre de tensōes e preocupaç̧̌es fisicas e mentais } \\
\text { confortável / despreocupado / sereno / tranquilidade } \\
\text { Satisfação } \\
\text { Desfrutar de um cumprimento recente de uma necessidade ou desejo } \\
\text { gratficado / satisfeito / contentamento / realizaçăo }\end{array}$ \\
\hline
\end{tabular}

Fonte: Desmet (2012). 
As 25 emoções descritas na Figura 1 representam o repertório geral de emoções humanas positivas, identificadas a partir da análise e classificação de 150 termos iniciais. Avaliando a similaridade entre os tipos de emoções, foi possível categorizá-las em nove grupos:

(a) empatia (simpatia, bondade, respeito);

(b) afeição (amor, admiração, devaneio);

(c) aspiração (luxúria, desejo, adoração);

(d) prazer (euforia, alegria, diversão);

(e) otimismo (esperança, antecipação);

(f) animação (surpresa, estímulo);

(g) confiança (coragem, orgulho, segurança);

(h) interesse (inspiração, encantamento, fascinação);

(i) contentamento (alívio, relaxamento, satisfação) (DESMET, 2012).

\section{Atributos do design biofílico}

O design biofílico busca soluções para as deficiências das edificações contemporâneas, estabelecendo novos meios que permitam a satisfação da experiência junto à natureza, no contexto da construção. O objetivo é a criação de "habitats" agradáveis ao ser humano, ambientes que qualifiquem a saúde e o bem-estar (KELLERT; CALABRESE, 2017).

Segundo Reeve et. al. (2012), um crescente número de pesquisadores vem explorando o impacto da natureza nos contextos urbanos. A indústria da construção civil tem despertado para a visão da biofilia, atenta em promover o contato com a natureza, considerado como experiência fundamental na qualidade de vida. Os mesmos autores (REEVE et. al., 2012) propuseram uma taxonomia de elementos biofílicos, sugerindo uma diversidade de possibilidades de aplicação. Os elementos foram categorizados de acordo com a escala de aplicação, iniciando por edificação, passando por vizinhança até a cidade propriamente dita.

Kaplan (1993) avalia a presença da natureza nos locais de trabalho como contribuição para o bemestar dos trabalhadores. O foco dos estudos de caso que o autor apresenta é dado pela presença ou ausência de janelas e vistas para a paisagem em locais de trabalho. As janelas são fontes de luz do sol, de informações sobre o clima e sobre outros acontecimentos do mundo exterior. Elas fornecem uma sugestão da extensão de onde se está no tempo e espaço. Os resultados sugerem que, para avaliar a importância da presença de uma janela, há que se avaliar também o que pode ser visto através dela. Se há apenas elementos construídos, os benefícios psicológicos não ocorrem. No entanto, se existem elementos da natureza, mesmo que apenas algumas árvores ou paisagismo simples, o efeito psicológico gerado é grande. Segundo Kaplan (1993), janelas fornecem um excelente meio para descansar a atenção, pois a possibilidade de desviar o olhar do trabalho por instantes e contemplar fragmentos da natureza constitui uma experiência renovadora para o usuário. A capacidade de desviar o olhar do trabalho por alguns instantes e experimentar fragmentos da natureza pode ser renovadora.

A teoria da restauração da atenção (ART), desenvolvida pelos autores Kaplan e Kaplan (1989 ${ }^{1}$ apud JOYE, 2007), interpreta a restauração como a recuperação da atenção dirigida ou a capacidade de se concentrar. Essa capacidade ocorre durante tarefas que exigem concentração profunda, como revisão ou estudo. Através da pesquisa de alguns autores (HARTIG et al., 2003² apud JOYE, 2007), descobriu-se que as configurações naturais são ideais para restaurar ou descansar a atenção direcionada.

De acordo com os estudos de Joye (2007), a imitação de elementos naturais na arquitetura e a concepção de ambientes que promovam o contato direto com a natureza podem levar o homem a experiências emocionais positivas e à redução do estresse. Contudo, o autor argumenta sobre a necessidade de abstração no processo de imitação da natureza, como as criações inspiradas nos modelos fractais da natureza, por exemplo, que tendem a trazer soluções de alto potencial criativo, por não estarem restritas à imitação literal de uma forma, mas à replicação de um princípio organizacional. Segundo o autor, os arquitetos podem ter uma noção intuitiva da importância da natureza como fonte de inspiração; porém, observando as edificações atuais, é visível como essa intuição está ainda distante da prática (JOYE, 2007).

Dentre os autores que abordam estratégias para aplicação do design biofílico, Kellert e Calabrese (2017) elencam atributos objetivos e os categorizam em três grupos: a experiência direta com a natureza; a experiência indireta com a natureza; a experiência de espacialidade e posicionamento. As três categorias estão ilustradas na Figura 2.

${ }^{2}$ HARTIG, T. et al. Tracking restoration in nat- ural and urban field settings. J ournal of Environ- mental Psychology, v. 23, 109-123, 2003. 
Figura 2 - Categorias e atributos do design biofílico
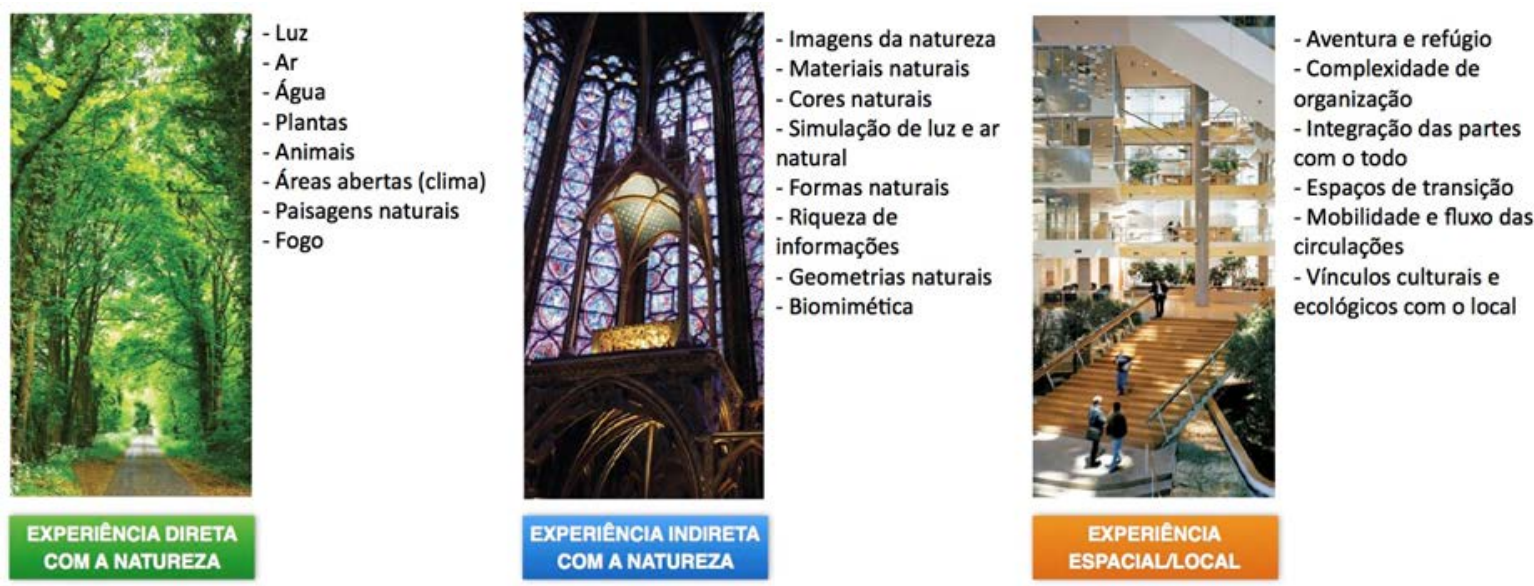

Fonte: adaptado de Kellert e Calabrese (2017)

A experiência direta com a natureza se refere ao contato direto com elementos, tais como luz e ar natural, plantas, animais, água, fogo, áreas abertas (clima) e paisagens naturais. A experiência indireta com a natureza se refere ao contato com representações ou imagens de referência, como fotos, quadros, materiais naturais e ornamentação inspirada em formas da natureza. Nesse grupo se encontram também o uso de cores naturais, as simulações de luz e ar natural, a riqueza de informações, as geometrias naturais e a biomimética. A terceira categoria aborda características espaciais próprias do mundo natural, como espaços que estimulam a aventura ou refúgio, a complexidade organizada, fluxos e circulações, integração das partes com o todo, espaços de transição, além de vínculos culturais e ecológicos com o local.

\section{Método}

Este item apresenta a caracterização e a estratégia da pesquisa, bem como a descrição dos métodos empregados para seu desenvolvimento. Do ponto de vista de seus objetivos, a pesquisa pode ser classificada como exploratória, pois visa proporcionar maior familiaridade com o problema de avaliação do ambiente construído (GIL, 1991). Quanto aos procedimentos, ela é classificada como estudo de caso. No que concerne à abordagem, ela é de caráter qualitativo e quantitativo, pois considera tanto a análise estatística de dados aferidos em escala quanto a opinião espontânea dos sujeitos nela envolvidos.

O caráter qualitativo se dá pelo interesse no significado das coisas, assim como pela compreensão das percepções e dos comportamentos humanos vinculados ao ambiente construído. Por outro lado, o caráter explicativo e quantitativo ocorre em função da necessidade de traduzir em números a graduação das emoções elencadas pelos usuários.

Com a finalidade de enriquecer a análise da interferência das emoções positivas no uso dos ambientes construídos e aproximar a visão do pesquisador às diversas variáveis existentes relacionadas a estes, buscou-se a utilização da avaliação pós-ocupação (APO) (ORNSTEIN, 1992), que é uma das metodologias correntes de avaliação de desempenho de ambientes construídos. Na APO de ambientes construídos, as atividades essencialmente estão divididas em etapas de coleta ou levantamento de dados, diagnóstico, recomendações para o ambiente (estudo de caso) e, finalmente, insumos para novos projetos. Nesta pesquisa, contudo, serão abordadas as primeiras etapas da APO, que consistem no levantamento de dados e diagnóstico, estruturada em nove etapas, descritas na Figura 3 (ORNSTEIN, 1992).

A primeira etapa consiste no levantamento das informações gerais do ambiente construído, seguida pela delimitação do público-alvo. A etapa seguinte se caracteriza pela coleta de dados dos usuários, mediante realização de entrevistas como pesquisa de satisfação. Os dados obtidos com os usuários são combinados e cruzados com as informações provenientes da literatura, tanto das emoções positivas (DESMET, 2012) como do design biofílico (KELLERT; CALABRESE, 2017). Com base no cruzamento dos dados, é possível realizar um diagnóstico qualitativo acerca da influência das emoções positivas no ambiente construído. 
Figura 3 - Nove etapas do método e estratégia de pesquisa

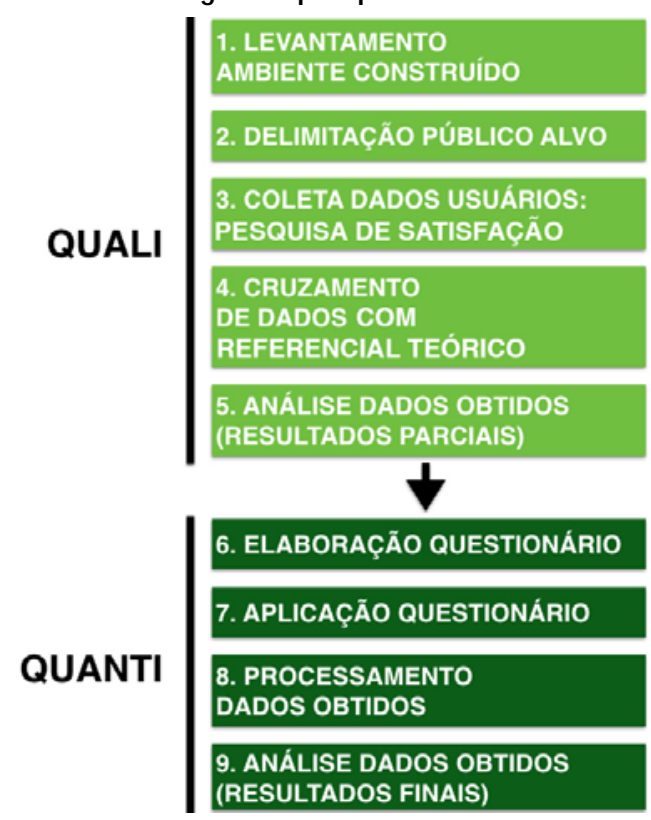

Os resultados parciais, obtidos nesta primeira fase qualitativa, são utilizados na elaboração de questionário específico para aplicação ao grupo de usuários selecionados. Os dados brutos adquiridos por meio da aplicação do questionário são processados e analisados para aferição do diagnóstico quantitativo proposto nesta pesquisa.

\section{Resultados e discussões}

O desenvolvimento de cada uma das nove etapas da metodologia é descrito a seguir. As informações resultantes de cada etapa são subsídio para o desenvolvimento das etapas seguintes.

\section{Levantamento do ambiente construído}

Para avaliar a relação dos atributos do design biofílico com as percepções e emoções dos usuários, foi selecionada uma edificação com características apropriadas para o estudo de caso. A presença evidente de atributos biofílicos, como paredes verdes e áreas abertas, levou à escolha do novo campus da Unisinos, em Porto Alegre, inaugurado em 2017, projeto do escritório AT Arquitetura. A construção dos $57.000 \mathrm{~m}^{2}$ levou cerca de dois anos e gerou interferências inclusive na estrutura viária no entorno, com ampliação da avenida principal, da rua lateral, criação de ciclovia e construção de passarela. De conceitos contemporâneos, a edificação chamou a atenção do público pelos múltiplos usos que promove, bem como pelos espaços ao ar livre e pela marcante estética das paredes verdes na fachada principal. A
Figura 4 apresenta perspectivas importantes da edificação.

É possível perceber a presença de diversos atributos do design biofílico no ambiente construído da Unisinos. As características biofílicas em destaque são: as amplas vistas das salas de aula para a paisagem; o aproveitamento da iluminação natural; o uso de materiais naturais (como pedras e madeira); as paredes verdes; a integração entre áreas abertas e espaços construídos; e a multiplicidade de usos adicionais às funções da universidade (teatro, lojas e restaurantes).

\section{Delimitação do público-alvo}

Circulam pela edificação e entorno um número grande de transeuntes, vizinhos, visitantes, consumidores, funcionários, alunos e professores. Diferentes tipos de usuários, com objetivos de uso e percepções distintas. Por essa razão, foi necessário delimitar o público-alvo para alcançar resultados mais consistentes para a pesquisa.

A delimitação ocorreu pela identificação do grupo de usuários que possui maior frequência $e$ permanência no uso das instalações, em detrimento dos usuários eventuais. O intuito foi realizar uma análise voltada às percepções do ambiente construído, no que se refere à qualidade do espaço universitário, considerando o estudo, trabalho e convívio promovidos no local. Foram então definidos como público-alvo os alunos da instituição, visto que possuem maior permanência e podem usufruir de praticamente todas as áreas da edificação. 
Figura 4 - Fotos do campus Unisinos Porto Alegre

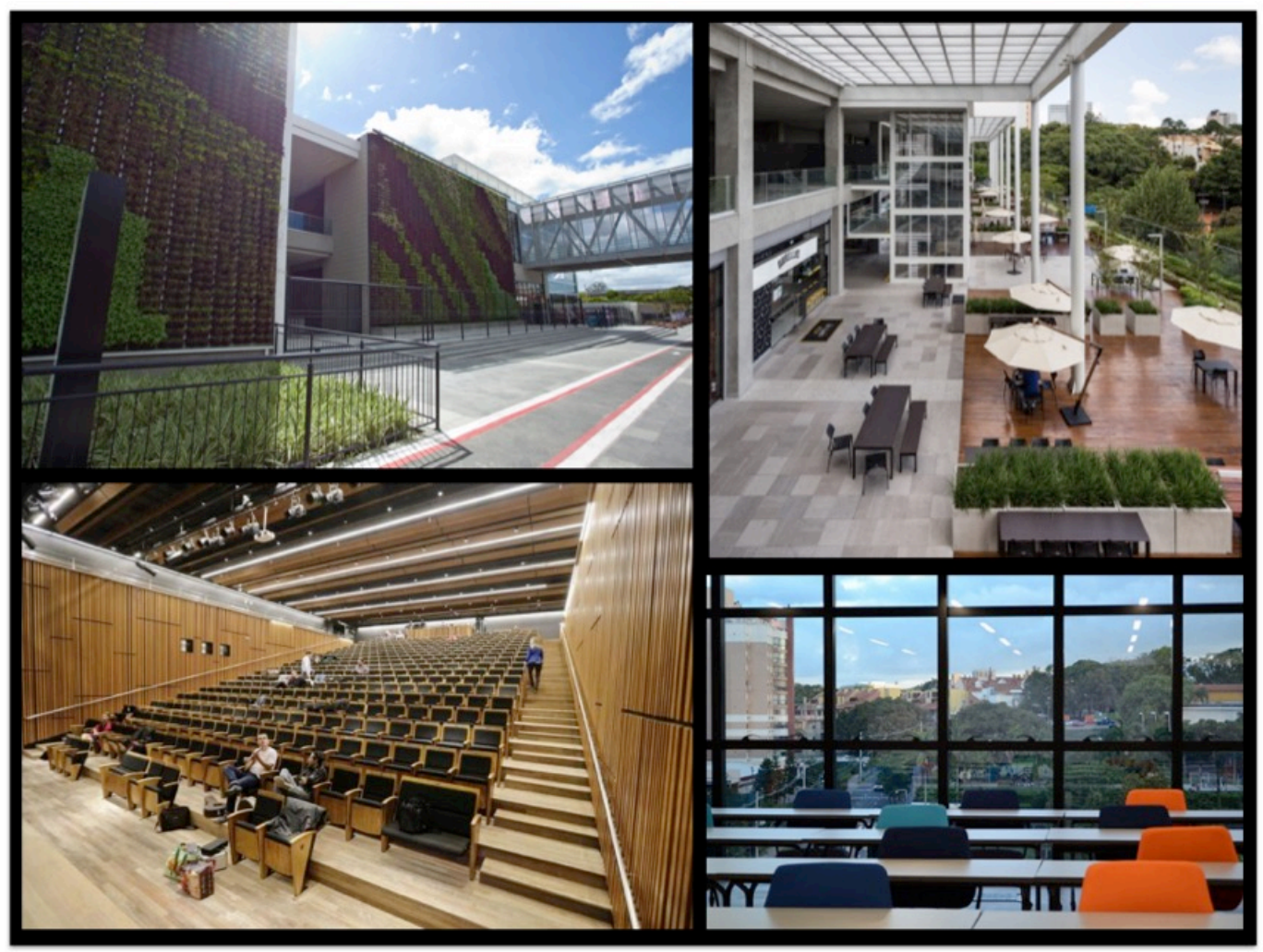

Fotos: Marcelo Donadussi (Cedidas por Atarquitetura em 2018).

A pesquisa inicial, de satisfação, foi realizada com alunos de diversos cursos e teve como objetivo mapear as suas percepções gerais. Para a aplicação do questionário, entretanto, foram selecionados apenas os alunos que cursam arquitetura, considerando que estes teriam mais conhecimento e predisposição para as percepções do espaço construído, além de maior interesse pelo tema, o que motivaria a participação na pesquisa.

\section{Coleta de dados dos usuários: pesquisa de satisfação}

A primeira aproximação com os usuários ocorreu por meio da pesquisa de satisfação, direcionada por perguntas amplas, abrindo espaço para a livre expressão de cada entrevistado a respeito das suas emoções e percepções quando em contato com o ambiente construído da Unisinos Porto Alegre.

As entrevistas foram realizadas em dupla de pesquisadores, com gravador de voz e anotações em papel. A abordagem ocorreu na saída das aulas, em espaço aberto, em um dia ensolarado e agradável, para motivar a participação na pesquisa. Buscou-se conversar com cada aluno individualmente, para que as respostas de uma pessoa não influenciassem nas respostas dos demais do grupo. As perguntas, na respectiva ordem, foram: (a) O que você acha do espaço deste campus novo da Unisinos Porto Alegre?

(b) Como você se sente quando interage com esse espaço? Por que você sente isso?

(c) Que elementos deste espaço podem estar associados às emoções citadas?

(d) A pesquisa de satisfação foi realizada com 21 usuários, até a identificação do ponto de saturação, quando as informações obtidas começaram a se repetir. O objetivo foi recolher informações a respeito dos atributos biofílicos do espaço construído bem como das emoções positivas identificadas espontaneamente nos relatos dos entrevistados, percebendo o que é mais valorizado e o que aparece com especial destaque. Com base nas informações adquiridas, foi possível iniciar o processo de análise de dados para posterior elaboração de questionário.

\section{Cruzamento de dados com referencial teórico}

O tratamento dos dados teve início com a transcrição da pesquisa de satisfação e identificação das emoções relatadas pelos usuários. Como delimitação, foram selecionadas para análise apenas as emoções positivas, excluindo todas as 
percepções negativas mencionadas, as quais podem ser mais bem exploradas em trabalhos futuros. Algumas das expressões utilizadas pelos alunos ao descreverem o campus foram: "sentimento de alegria e ao mesmo tempo de tranquilidade", "aqui tem com o que se ocupar, não é como no outro campus que não tinha o que fazer", "a passarela é muito massa", "sensacional", "sensação boa de segurança", "a estrutura é moderna e completa, dá vontade de estudar".

Em seguida, foram investigadas as 25 emoções positivas de Desmet (2012), buscando compreendêlas para auxiliar na interpretação de cada expressão citada pelos usuários, o que possibilitou a realização das associações devidas. Em paralelo com o estudo das emoções, seguiu-se a investigação a respeito dos atributos do design biofílico, embasados na obra dos autores Kellert e Calabrese (2017). A compreensão dos atributos possibilitou a análise e posterior associação com os relatos dos usuários do espaço construído.

O cruzamento dos dados entre a pesquisa de satisfação com os usuários e o referencial teórico constam na Figura 5, a qual aborda as interpretações das percepções dos alunos, associadas a uma ou mais emoções positivas e aos atributos biofílicos do ambiente construído.

\section{Análise dos dados obtidos: resultados parciais}

No cruzamento dos relatos dos usuários com o referencial teórico, identificaram-se os atributos biofílicos mais marcantes para os alunos, bem como as emoções positivas mais elicitadas pelo ambiente construído. Dentre os 24 atributos do design biofílico, apenas 12 apareceram na pesquisa de satisfação:
(a) luz natural;
(b) vegetação;
(c) áreas abertas (clima);
(d) paisagens naturais;
(e) materiais naturais;
(f) exploração e refúgio;
(g) complexidade organizada;
(h) integração das partes com o todo;
(i) espaços de transição;
(j) mobilidade e sinalização; e
(k) vínculos culturais e ecológicos.

\section{Figura 5 - Parte das interpretações dos relatos dos usuários e associação com emoções positivas e com} atributos do design biofílico

\begin{tabular}{|c|c|c|}
\hline ENTREVISTA USUÁRIOS & ATRIBUTOS DESIGN BIOFILICO & EMOCOES POSITIVAS \\
\hline gosta, pois tem acesso locais com sol & LUZ NATURAL, ÁREAS ABERTAS (CLIMA) & RELAXAMENTO \\
\hline gosta da amplitude espaço externo & $\begin{array}{l}\text { ÁREAS ABERTAS (CLIMA), PAISAGENS } \\
\text { NATURAIS }\end{array}$ & ESTIMULO, RELAXAMENTO, ENCANTAMENTO \\
\hline valoriza funcionalidade da estrutura interna & $\begin{array}{l}\text { MOBILIDADE E SINALIZAÇÃO, COMPLEXIDADE } \\
\text { ORGANIZADA }\end{array}$ & CONFIANÇA \\
\hline sente que o ambiente do Campus proporciona a produtividade & & ESTÍMULO \\
\hline $\begin{array}{l}\text { Cadeiras das salas de aula tem rodizio o que permite } \\
\text { flexibilidade de uso }\end{array}$ & MOBILIDADE E SINALIZAÇÃO & SATISFAÇÃO, SIMPATIA \\
\hline $\begin{array}{l}\text { Salas de aula são boas: são horizontais, o professor fica } \\
\text { próximo, cadeiras móveis, paredes livres para escrever }\end{array}$ & MOBILIDADE E SINALIZAÇÃO & SATISFAÇÃO, SIMPATIA \\
\hline $\begin{array}{l}\text { espaço muito funcional e tecnológico: oferece tudo o que os } \\
\text { alunos precisam }\end{array}$ & & GENTILEZA, CONFIANÇA, SATISFAÇÃO \\
\hline salas de aula são confortáveis & EXPLORAÇÃO E REFÚGIO & GENTILEZA, SATISFAÇÃO \\
\hline sala de aula são acessiveis e dinâmicas & EXPLORAÇÃO E REFÚGIO & ESTIMULO, INSPIRAÇÃO \\
\hline Gosta muito das paredes "riscáveis" das salas de aula & EXPLORAÇÃO E REFÚGIO & CORAGEM, ESTIMULO, SURPRESA, INSPIRAÇÃO \\
\hline $\begin{array}{l}\text { o oitavo andar é muito bom pois possibilita remoção das } \\
\text { paredes, compondo um grande salão }\end{array}$ & ESPAÇOS DE TRANSIÇÃO & \\
\hline $\begin{array}{l}\text { Felicidade e tranquilidade. Não sente angústia, pois espaço } \\
\text { proporciona o que fazer, como se ocupar. }\end{array}$ & $\begin{array}{l}\text { COMPLEXIDADE ORGANIZADA, EXPLORAÇÃO } \\
\text { E REFÚGIO }\end{array}$ & ALEGRIA, DIVERSÃO, SATISFAÇÃO \\
\hline $\begin{array}{l}\text { Não se sente preocupado nem nervoso. Sensação boa por } \\
\text { poder usar todo esse espaço }\end{array}$ & $\begin{array}{l}\text { COMPLEXIDADE ORGANIZADA, EXPLORAÇÃO } \\
\text { E REFÚGIO }\end{array}$ & ADMIRAÇÃO, ALEGRIA, RELAXAMENTO \\
\hline o espaço tem praticidade e organização & COMPLEXIDADE ORGANIZADA & CONFIANÇA, RESPEITO \\
\hline gosta das flores, árvores (presença da vegetação) & VEGETAÇÃO & $\begin{array}{l}\text { ALEGRIA, ENCANTAMENTO, RELAXAMENTO, } \\
\text { SATISFAÇÃO }\end{array}$ \\
\hline Beleza & & SATISFAÇÃO, ALEGRIA \\
\hline $\begin{array}{l}\text { Janelas das salas de aula são boas pois as vistas são amplas } \\
\text { e entra muita luz. }\end{array}$ & LUZ NATURAL, PAISAGENS NATURAIS & $\begin{array}{l}\text { RELAXAMENTO, SATISFAÇÃO, INSPIRAÇÃO. ALEGRIA, } \\
\text { ESTÍMULO }\end{array}$ \\
\hline alegria & & ALEGRIA \\
\hline Parede verde e telhado verde, sustentabilidade e beleza & $\begin{array}{l}\text { VEGETAÇÃO, VÍNCULOS CULTURAIS E } \\
\text { ECOLOGICOS }\end{array}$ & $\begin{array}{l}\text { ORGULHO, RESPEITO, SIMPATIA, INSPIRAÇÃO, } \\
\text { SATISFAÇẤO }\end{array}$ \\
\hline área de convivência próxima aos restaurantes é inovadora & EXPLORAÇÃO E REFÚGIO & SATISFAÇÃO, ENCANTAMENTO, ORGULHO, SURPRESA \\
\hline inovação & EXPLORAÇÃO E REFÚGIO & ORGULHO, SURPRESA, ADMIRAÇÃO, \\
\hline tranquilidade & EXPLORAÇÃO E REFÚGIO & ALIVIO, RELAXAMENTO, SATISFAÇÃO \\
\hline $\begin{array}{l}\text { tranquilidade pela vista da vegetação pelas janelas das salas } \\
\text { de aula }\end{array}$ & $\begin{array}{l}\text { PAISAGENS NATURAIS, ÁREAS ABERTAS } \\
\text { (CLIMA) }\end{array}$ & $\begin{array}{l}\text { RELAXAMENTO, SATISFAÇÃO, INSPIRAÇÃO. ALEGRIA, } \\
\text { ESTIMULO }\end{array}$ \\
\hline Prazer pelo espaço de convivência na área dos restaurantes & $\begin{array}{l}\text { EXPLORAÇÃO E REFÚGIO, ESPAÇOS DE } \\
\text { TRANSIÇÃO }\end{array}$ & SIMPATIA, ALEGRIA \\
\hline
\end{tabular}


Das 25 emoções positivas de Desmet, 15 foram identificadas nos relatos dos alunos:
(a) simpatia;
(b) gentileza;
(c) respeito;
(d) admiração;
(e) alegria;
(f) diversão;
(g) surpresa;
(h) estímulo;
(i) coragem;
(j) orgulho;
(k) confiança;
(l) inspiração;
(m) encantamento;
(n) relaxamento; e
(o) satisfação.

A Figura 6 sintetiza os atributos biofílicos e as emoções positivas identificadas após a realização da pesquisa de satisfação com os usuários.
A partir dos dados obtidos, foi possível inferir informações qualitativas a respeito do tema das emoções positivas, associadas aos atributos do design biofílico. A etapa seguinte focou na elaboração de questionário, cujo objetivo foi transpor as informações qualitativas obtidas na pesquisa de satisfação em dados quantitativos.

\section{Elaboração do questionário}

Com os resultados da etapa qualitativa da pesquisa, elaborou-se um questionário específico com o intuito de identificar a intensidade das emoções positivas percebidas pelo usuário, quando em contato com cada um dos atributos biofílicos da edificação. Para isso, foram vinculadas determinadas emoções ao lado de cada atributo biofílico, sendo estes últimos reforçados pela presença de fotos que permitissem ao participante recordar-se dos elementos e ambientes da edificação. Os vínculos estabelecidos entre as emoções positivas e os atributos biofílicos não foram arbitrados pelos autores, mas provêm dos relatos dos entrevistados. Por isso, cada atributo tem ao seu lado um conjunto distinto de emoções, podendo haver repetições de emoções em diferentes atributos.

Figura 6 - Identificação de atributos biofílicos e emoções positivas nos relatos dos usuários

\begin{tabular}{|c|c|c|}
\hline \multicolumn{3}{|c|}{ ATRIBUTOS DESIGN BIOFÍLICO } \\
\hline GRUPO & ORIGINAL & TRADUÇÃO \\
\hline \multirow{8}{*}{$\begin{array}{l}\text { EXPERIÊNCIA } \\
\text { DIRETA DA } \\
\text { NATUREZA }\end{array}$} & \multirow{8}{*}{$\begin{array}{l}\text { Light } \\
\text { Air } \\
\text { Water } \\
\text { Plants } \\
\text { Animals } \\
\text { Weather } \\
\text { Natural Landscapes and } \\
\text { esosystems } \\
\text { Fire }\end{array}$} & Luz natural \\
\hline & & Ventilaçäo natural \\
\hline & & Água \\
\hline & & Vegetação \\
\hline & & Animais \\
\hline & & Áreas abertas (clima) \\
\hline & & Paisagens naturais \\
\hline & & Fogo \\
\hline \multirow{9}{*}{$\begin{array}{l}\text { EXPERIÊNCIA } \\
\text { INDIRETA DA } \\
\text { NATUREZA }\end{array}$} & \multirow{3}{*}{$\begin{array}{l}\text { Images of nature } \\
\text { Natural materials } \\
\text { Natural colors }\end{array}$} & Imagens de natureza \\
\hline & & Materiais naturais \\
\hline & & Cores naturais \\
\hline & Simulating natural light and air & Simulação de iluminação e ventilação \\
\hline & Naturalistic shapes and forms & Formas naturalistas (literal) \\
\hline & Evoking nature & Evocação da natureza (não literal) \\
\hline & Information richness & Riqueza de informaçöes \\
\hline & Age, change, and the patina of & "o passar do tempo" \\
\hline & $\begin{array}{l}\text { Natural geometry } \\
\text { Biomimicry }\end{array}$ & $\begin{array}{l}\text { Geometrias naturais } \\
\text { Biomimética }\end{array}$ \\
\hline \multirow{6}{*}{\begin{tabular}{|l} 
EXPERIÊNCIA \\
ESPACIAL/LOCAL
\end{tabular}} & \multirow{6}{*}{$\begin{array}{l}\text { Prospect and refuge } \\
\text { Organized complexity } \\
\text { Integration of parts to wholes } \\
\text { Transitional spaces } \\
\text { Mobility and wayfinding } \\
\text { Cultural and ecological } \\
\text { attachment to place }\end{array}$} & Exploração e refúgio \\
\hline & & Complexidade organizada \\
\hline & & Integração das partes com o todo \\
\hline & & Espaços de transição \\
\hline & & Mobilidade e sinalização \\
\hline & & Vínculos culturais e ecológicos \\
\hline
\end{tabular}

\begin{tabular}{|c|c|c|}
\hline \multicolumn{3}{|c|}{ EMOÇÕES POSITIVAS } \\
\hline GRUPO & ORIGINAL & TRADUÇĀO \\
\hline $\begin{array}{l}\text { EMPATIA } \\
\text { Empathy }\end{array}$ & $\begin{array}{l}\text { Sympathy } \\
\text { Kindness } \\
\text { Respect }\end{array}$ & \begin{tabular}{|l|} 
Simpatia \\
Gentileza \\
Respeito \\
\end{tabular} \\
\hline \multirow[t]{2}{*}{$\begin{array}{l}\text { AFEIÇÃo } \\
\text { Affection }\end{array}$} & $\begin{array}{l}\text { Love } \\
\text { Admiration }\end{array}$ & $\begin{array}{l}\text { Amor } \\
\text { Admiração }\end{array}$ \\
\hline & Dreaminess & Sonho \\
\hline $\begin{array}{l}\text { ASPIRAÇÃO } \\
\text { aspiraton }\end{array}$ & $\begin{array}{l}\text { Lust } \\
\text { Desire } \\
\text { Worship }\end{array}$ & $\begin{array}{l}\text { Luxúria } \\
\text { Desejo } \\
\text { Adoração }\end{array}$ \\
\hline PRAZER & Euphoria & Euforia \\
\hline enjoyment & $\begin{array}{l}\text { Joy } \\
\text { Amusement }\end{array}$ & \begin{tabular}{|l|} 
Alegria \\
Diversão \\
\end{tabular} \\
\hline отIMISTMO & hope & Esperança \\
\hline Optimism & anticipaion & Antecipação \\
\hline \multirow{3}{*}{$\begin{array}{l}\text { ANIMAÇÃo } \\
\text { Animation } \\
\text { SEGURANÇA } \\
\text { Assurance }\end{array}$} & $\begin{array}{l}\text { Surprise } \\
\text { Energized }\end{array}$ & \begin{tabular}{|l|} 
Surpresa \\
Estímulo \\
\end{tabular} \\
\hline & $\begin{array}{l}\text { Courage } \\
\text { Pride }\end{array}$ & \begin{tabular}{|l|} 
Coragem \\
Orgulho \\
\end{tabular} \\
\hline & Confidence & Confiança \\
\hline $\begin{array}{l}\text { INTERESSE } \\
\text { Interest }\end{array}$ & $\begin{array}{l}\text { Inspiration } \\
\text { Enchantment } \\
\text { Fascination }\end{array}$ & \begin{tabular}{|l|} 
Inspiração \\
Encantamento \\
Fascinação
\end{tabular} \\
\hline \multicolumn{2}{|c|}{ CONTENTAMENTO Relief } & Alívio \\
\hline Gratification & $\begin{array}{l}\text { Relaxation } \\
\text { Satisfaction }\end{array}$ & \begin{tabular}{|l|} 
Relaxamento \\
Satisfação \\
\end{tabular} \\
\hline
\end{tabular}


A escala de graduação escolhida para a avaliação dos participantes foi de 1 a 7 . Considera-se 1 para menor e 7 para maior intensidade de percepção de determinada emoção, relacionada à presença de cada atributo biofílico do ambiente construído. O questionário também se propunha a indicar qual a ordem de relevância dos atributos biofílicos da edificação, ou seja, aqueles que são mais apreciados pelos usuários. Para isso, foi criada uma sequência de campos, ao final da página, a ser preenchida com os atributos (de 1 a 8 ) na posição de primeiro a último lugar, conforme a ordem de relevância percebida pelo aluno (Figura 7).

\section{Aplicação do questionário}

O questionário foi aplicado em quatro turmas do curso de arquitetura, em semestres iniciais, no campus Unisinos Porto Alegre: três turmas no turno da manhã e uma no turno da noite, totalizando 102 participantes. A atividade ocorreu presencialmente e durante o horário de aula. De forma muito breve, em torno de cinco minutos, os pesquisadores passaram orientações a respeito do tema e do preenchimento do questionário. O tempo médio para a conclusão das respostas foi de aproximadamente dez minutos.

Durante a realização do trabalho foi possível perceber entre os alunos diferentes graus de envolvimento e dedicação. Alguns ficaram mais silenciosos e concentrados durante o preenchimento, enquanto outros não pararam de conversar e tinham a atenção dividida entre o questionário e os colegas. Outra diferença percebida foi o tempo despendido no preenchimento, que variou de aproximadamente três a quinze minutos. Enquanto alguns se dedicavam em compreender e pensar sobre os pontos abordados, outros pareciam mais preocupados em terminar rápido do que em refletir com profundidade a respeito de cada questão.

\section{Processamento dos dados obtidos no questionário}

Com os 102 questionários respondidos foi possível iniciar o trabalho de leitura e análise dos dados. A primeira análise ocorreu com relação à graduação das emoções positivas vinculadas a cada atributo biofílico. Para tanto, foi realizado um somatório simples do valor (de 1 a 7) atribuído por cada aluno a cada emoção. Dessa forma, foi possível verificar a intensidade de cada emoção para cada atributo.

Para hierarquizar a relevância/importância de cada atributo biofílico, segundo a percepção dos usuários (última informação solicitada no questionário), foram atribuídos valores decrescentes para cada posição hierárquica. Dessa forma, a informação inserida na primeira posição recebeu pontuação 80; na segunda posição, 70; na terceira posição, 60; na quarta posição, 50; na quinta posição, 40; na sexta posição, 30; na sétima posição, 20 e na última posição, 10, conforme indica a Figura 8.

Com o intuito de determinar a confiabilidade do questionário aplicado, utilizou-se o coeficiente alfa de Cronbach (CORTINA, 1993). Almeida, Santos e Costa (2010) reiteram que o índice de alfa abaixo de 0,70 significa uma consistência interna baixa e que o máximo esperado é 0,90 , pois resultados acima desse valor indicam redundância. Segundo Streiner (2003), os índices indicados para uma boa consistência interna variam de alfa entre 0,80 e 0,90. O levantamento de dados dos questionários aplicados permitiu a análise objetiva da relação das emoções positivas vinculadas aos atributos biofílicos do ambiente construído, demonstrada por diferentes gráficos estatísticos.

\section{Análise dos dados obtidos: resultados finais}

Segundo as informações obtidas, as emoções positivas elicitadas pelos usuários em maior intensidade em contato com cada atributo são:

(a) materiais naturais da edificação encantamento, satisfação e relaxamento;

(b) espaços ao ar livre - satisfação, encantamento e alegria;

(c) vistas para a paisagem - satisfação, encantamento e relaxamento;

(d) elementos construtivos inusitados admiração, encantamento e surpresa;

(e) luz natural - satisfação, relaxamento e alegria;

(f) dinamicidade das salas de aula - satisfação, estímulo e inspiração;

(g) diversidade de funções - admiração, satisfação; e

(h) paredes verdes - encantamento, satisfação e relaxamento. 
Figura 7 - Questionário elaborado

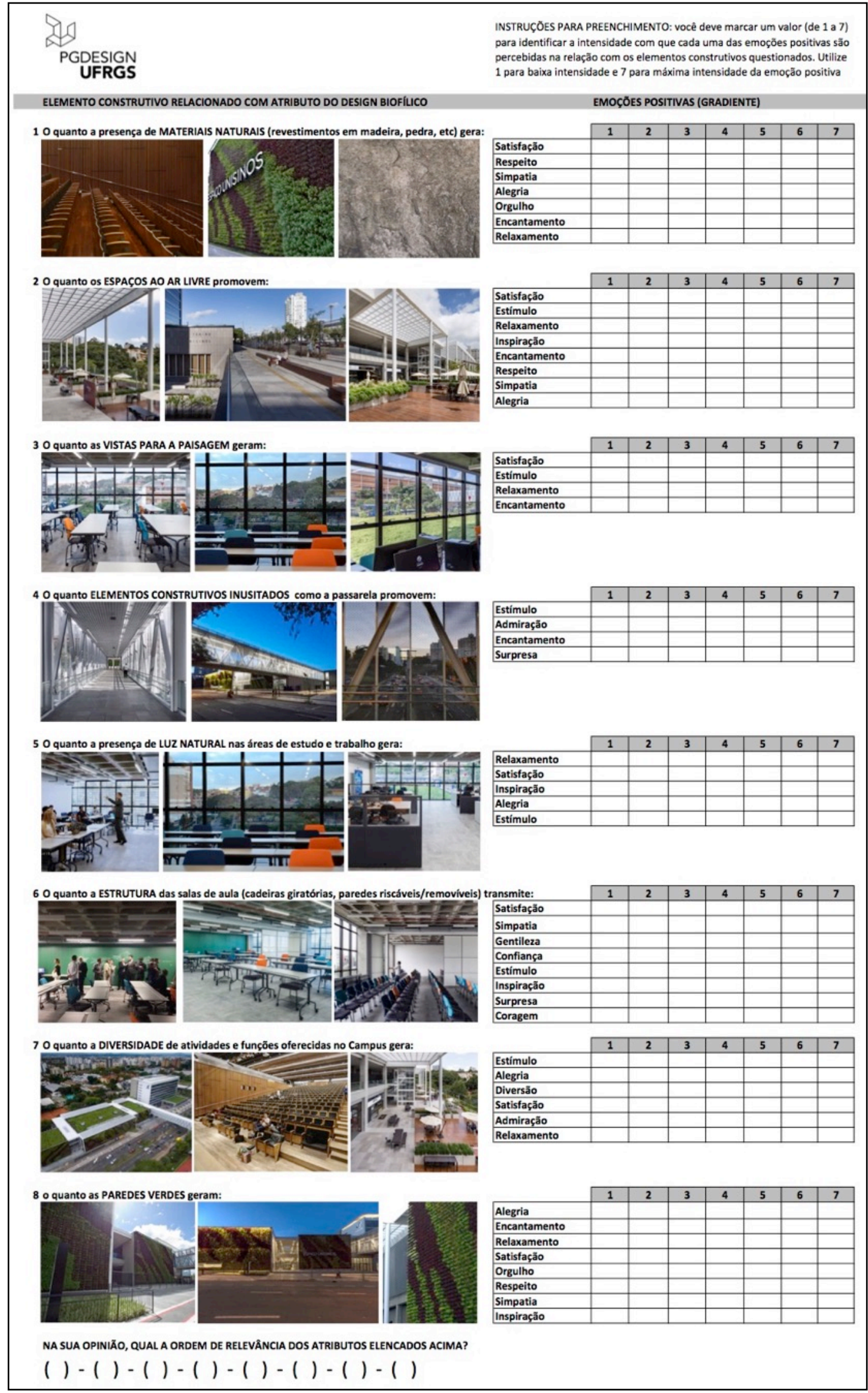

Emoções positivas no uso do espaço construído de um campus universitário associadas aos atributos do design 47 biofílico 
Figura 8 - Pontuação atribuída a cada posição na ordem de relevância dos atributos biofílicos

\begin{tabular}{|c|c|c|c|c|c|c|c|}
\hline ( ) & $(1)$ & (1) & (1) & ( ) & (1) & (1) & (1) \\
\hline 12 POSIÇÃO & 29 POSIÇÃO & $3^{2}$ POSIÇÃO & 49 POSIÇÃO & 59 POSIÇÃO & 69 POSIÇÃO & $7^{9}$ POSIÇÃO & $8^{9}$ POSIÇÃO \\
\hline 80 pontos & 70 pontos & 60 pontos & 50 pontos & 40 pontos & 30 pontos & 20 pontos & 10 pontos \\
\hline
\end{tabular}

De acordo aos autores Kellert e Calabrese (2017), os materiais trazidos da natureza frequentemente elicitam respostas táteis e visuais positivas no usuário. Conforme indicam os gráficos da Figura 9, a maior parte dos alunos, em contato com os materiais naturais, enfatiza a emoção positiva de encantamento, explicada por Desmet (2012) como sentir-se cativado por algo prazeroso ou extraordinário. Já as percepções e experiências ao ar livre, no contexto da edificação, costumam gerar ao mesmo tempo satisfação e estímulo (KELLERT; CALABRESE, 2017). Os dados extraídos dos questionários relacionam os espaços ao ar livre com a emoção positiva de satisfação, descria por Desmet (2012) como desfrutar da realização de alguma necessidade ou desejo.

Mesmo em contextos ordinários, paisagens naturais são preferidas pela maioria das pessoas, em vez de cenários artificiais (KELLERT; CALABRESE, 2017). Como mostra a Figura 10, as vistas para a paisagem, a partir da edificação, foram relacionadas principalmente à emoção positiva de satisfação. O atributo do design biofílico exploração e refúgio se relaciona a elementos da edificação que promovam oportunidade e perigo, por um lado, e proteção e segurança por outro. Os elementos construtivos inusitados, como a passarela, são associados pelos alunos com a emoção positiva de admiração, explicada por Desmet (2012) como experimentar um impulso de apreciação ou estima vinculado ao mérito ou conquista.

A experiência da luz natural é fundamental para saúde e bem-estar do ser humano, facilita o deslocamento e contribui para o conforto (KELLERT; CALABRESE, 2017). A maior parte dos alunos enfatiza, em contato com a luz natural, a emoção positiva de satisfação (Figura 11). Já a dinamicidade das salas de aula, que se associa ao atributo biofílico de mobilidade e sinalização, gera sentimentos de apropriação e segurança no uso, eliminando confusão e ansiedade. Em contato com esse atributo, a emoção positiva mais destacada foi novamente a satisfação (Figura 11).

A diversidade de funções relaciona-se ao atributo biofílico da complexidade organizada, o que significa lugares ricos em experiências e oportunidades, com características de boas conexões e coerência entre as partes (KELLERT;
CALABRESE, 2017). Foi associado pelos alunos, principalmente à emoção positiva de admiração, como impulso de apreciação ou estima (Figura 12). Por sua vez, as paredes verdes se relacionam ao atributo de vegetação e às experiências de contato direto com a natureza. É uma das estratégias do design biofílico de maior sucesso, pois a presença da vegetação pode reduzir o estresse, contribuir para a saúde, aumentar o conforto, o desempenho e a produtividade (KELLERT; CALABRESE, 2017). Foi mais intensamente associada à emoção positiva do encantamento, fazendo as pessoas se sentirem cativadas por algo prazeroso ou extraordinário (Figura 12).

É possível observar que as emoções encantamento e satisfação foram as primeiras em intensidade de percepção do usuário para quase todos os atributos do design biofílico. Outras emoções positivas que se destacam nas repostas foram relaxamento, admiração, alegria e estímulo. As emoções positivas menos enfatizadas no questionário pelos usuários foram orgulho, respeito, coragem, gentileza e diversão.

Por meio da comparação entre os gráficos acima, foi possível identificar qual dos atributos biofílicos estimula mais cada emoção. No gráfico da Figura 13 estão indicados os atributos do ambiente construído que melhor promovem as emoções positivas no estudo de caso. De todos eles, as paredes verdes se destacam como o atributo de maior impacto nas emoções dos usuários.

Dentre as emoções positivas analisadas, satisfação, admiração e encantamento obtiveram destaque nos diversos atributos avaliados, ocupando o primeiro ou segundo lugar nas mensurações em que constaram. Satisfação aparece como a emoção mais intensa na percepção dos espaços ao ar livre, vistas para as paisagens, luz natural e dinamicidade das salas de aula. Encantamento se destaca como a principal emoção quando os alunos se referem aos materiais naturais, aos elementos inusitados e às paredes verdes. Por fim, a admiração define o sentimento por elementos construtivos inusitados, tais como a passarela.

São as três emoções que melhor expressam o modo positivo como os alunos que responderam à pesquisa percebem o ambiente construído do novo campus Unisinos, o que confirma a abordagem de 
Kellert e Calabrese (2017) sobre a necessidade da criação de "habitats" que propiciem o bem-estar e a satisfação do usuário.
Retomando as três categorias básicas do design biofílico (KELLERT; CALARESE, 2017), são identificadas as emoções positivas correspondentes que mais se destacam em cada grupo (Figura 14).

Figura 9 - Intensidade das emoções para atributos materiais naturais e espaços ao ar livre

MATERIAIS NATURAIS

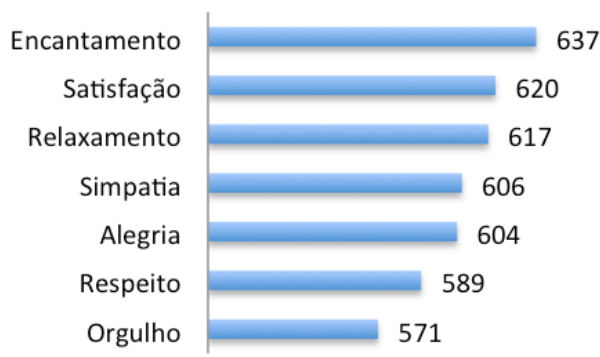

ESPAÇOS AO AR LIVRE

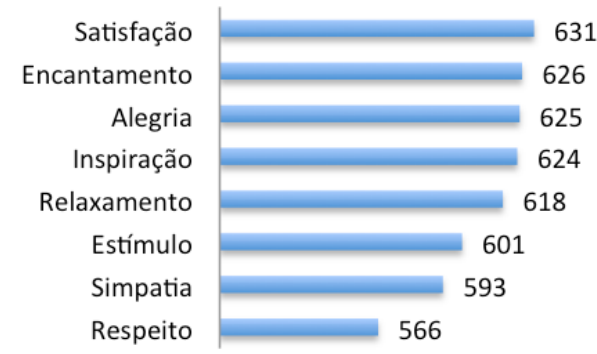

Figura 10 - Intensidade das emoções para atributos vistas para a paisagem e elementos construtivos inusitados
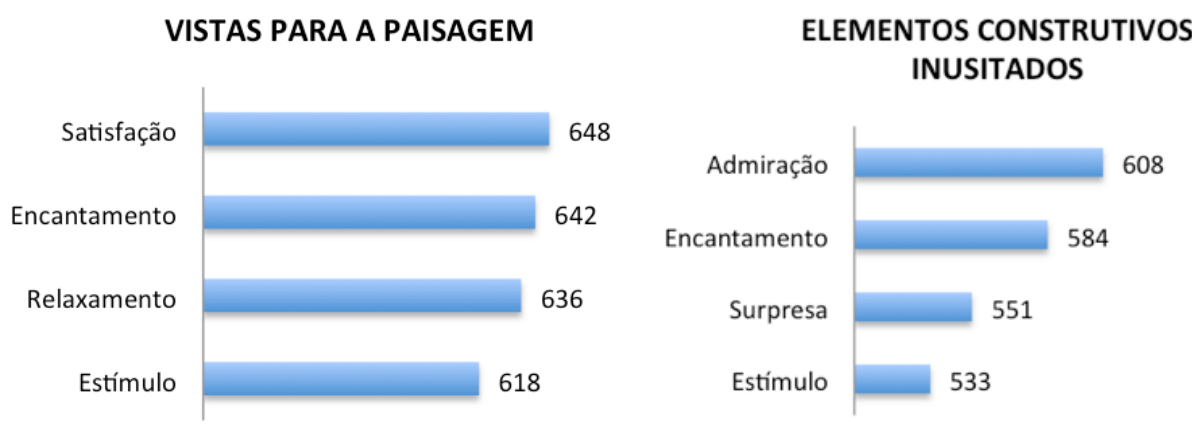

Figura 11 - Intensidade das emoções para atributos luz natural e dinamicidade das salas de aula LUZ NATURAL DINAMICIDADE SALAS DE AULA

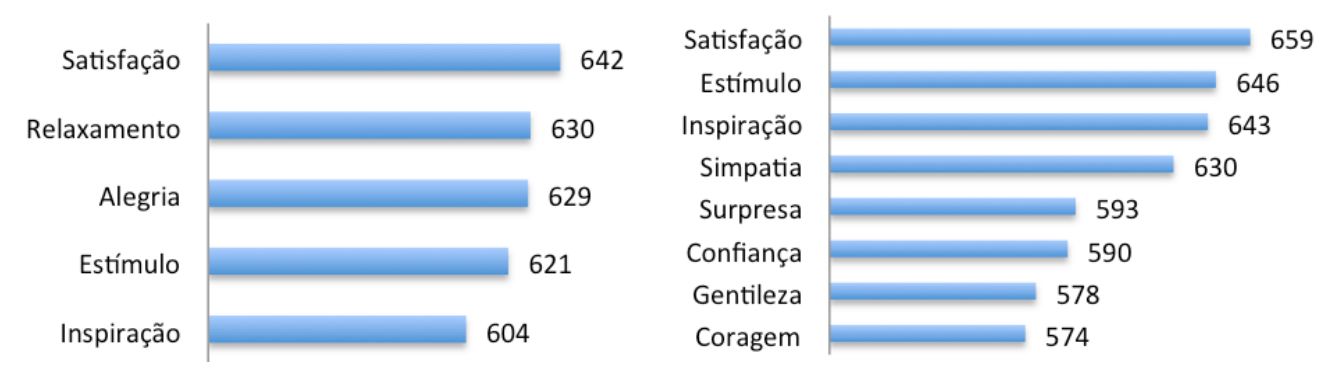

Figura 12 - Intensidade das emoções para atributos diversidade de funções e paredes verdes DIVERSIDADE DE FUNÇÕES PAREDES VERDES

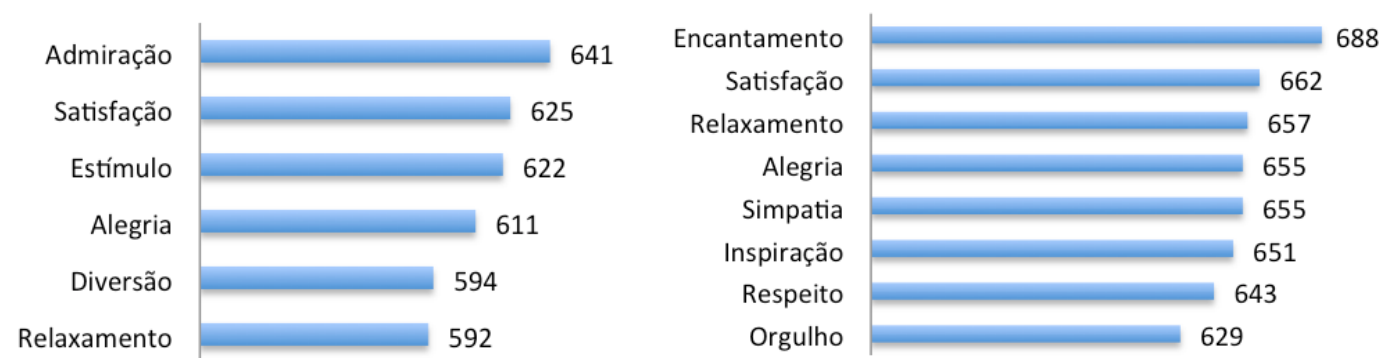

Emoções positivas no uso do espaço construído de um campus universitário associadas aos atributos do design 49 
Figura 13 - Comparativo das emoções positivas relacionadas aos atributos do design biofílico

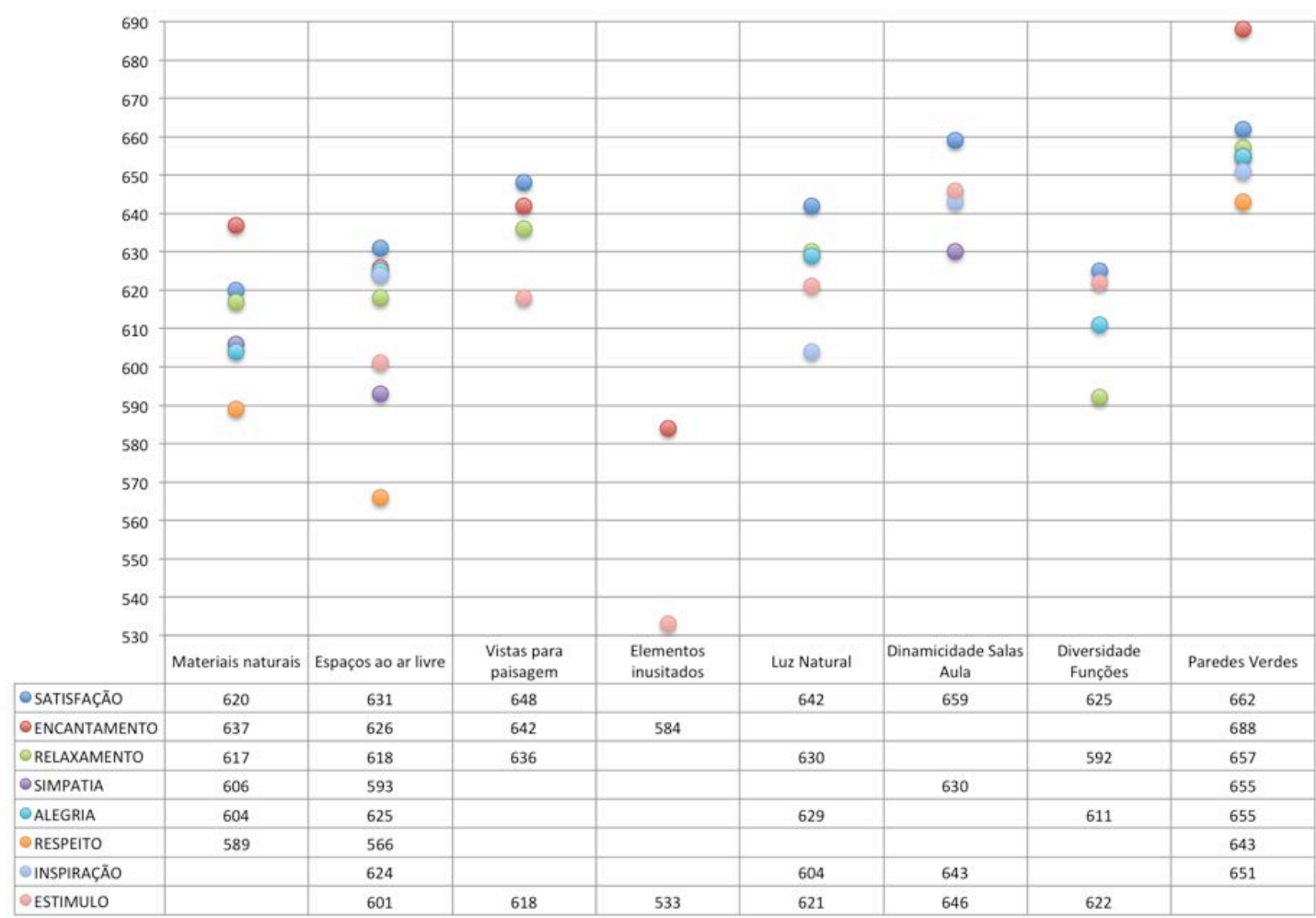

Figura 14 - Emoções com maior intensidade nas três categorias básicas do design biofílico

\begin{tabular}{|c|c|}
\hline $\begin{array}{l}\text { EXPERIÊNCIA DIRETA } \\
\text { COM A NATUREZA }\end{array}$ & $\begin{array}{l}\text { emoções com maior intensidade } \\
\text { SATISFAÇÃO RELAXAMENTO } \\
\text { ENCANTAMENTO }\end{array}$ \\
\hline $\begin{array}{l}\text { EXPERIÊNCIA INDIRETA } \\
\text { COM A NATUREZA }\end{array}$ & $\begin{array}{c}\text { ENCANTAMENTO SATISFAÇÄO } \\
\text { ADMIRAČÃO }\end{array}$ \\
\hline $\begin{array}{l}\text { EXPERIÊNCIA } \\
\text { ESPACIAL / LOCAL }\end{array}$ & $\begin{array}{c}\text { SATISFAÇÃO ENCANTAMENTO } \\
\text { ADMIRACCÃO } \quad \text { ESTIMULO }\end{array}$ \\
\hline
\end{tabular}

Outro resultado extraído do questionário mensura a importância de cada atributo biofílico presente na edificação (Figura 15). Para isso, solicitou-se aos alunos, no final do questionário, que colocassem em ordem de relevância os atributos de sua preferência, cujo resultado foi:

(a) (1) espaços ao ar livre;

(b) (2) luz natural;

(c) (3) dinamicidade das salas de aula;

(d) (4) vistas para a paisagem;

(e) (5) paredes verdes;

(f) (6) diversidade de funções;

(g) (7) materiais naturais; e

(h) (8) elementos construtivos inusitados.
Observa-se que os atributos espaços ao ar livre, luz natural e dinamicidade das salas de aula obtiveram índices expressivos na preferência, comparado aos demais, superando a mensuração de 5.300. Esses dados vão ao encontro dos reportados por Browning e Cooper (2017), os quais, focados na análise de escritórios, destacaram a iluminação natural com 44\% na preferência dos elementos desejados.

O coeficiente de alfa de Cronbach foi aplicado com referência nas respostas obtidas em cada um dos atributos avaliados, nos quais os índices resultantes ficaram dentro do intervalo indicado por Streiner, de 0,80 e 0,90 . Vale ressaltar que o índice de 0,92 obtido como resultado na avaliação do atributo 7 pode indicar uma redundância das emoções avaliadas. No entanto, o índice final, que avalia o questionário como um todo, obteve o valor de 0,86 , indicando uma boa consistência interna, o que 
estabelece a confiabilidade almejada para o questionário aplicado. A Figura 16 indica o coeficiente de alfa de Cronbach aplicado para os oito atributos e para a pesquisa como um todo. As colunas correspondentes à turma 10 representam parte do total de 102 alunos considerados para a obtenção dos índices do alfa de Cronbach.

\section{Considerações finais}

Com base no referencial teórico nas áreas de design e emoção e design biofílico, foi possível traçar correlações entre elas, resultando nos quesitos de avaliação e análise. A pesquisa associou, de modo qualitativo e quantitativo, os atributos do design biofílico com as emoções positivas, atingindo o objetivo de avaliar as percepções do usuário em contato com a edificação. Confirmando a abordagem dos autores Nassar (1994) e Küller (1980), que destacam a importância das emoções como modificadoras das experiências na interação com os espaços, os resultados desta pesquisa contribuem para a aproximação do campo de estudo do design e emoção para a avaliação do ambiente construído.

Figura 15 - Ordem de relevância dos atributos do design biofílico

\section{RELEVÂNCIA DOS ATRIBUTOS}

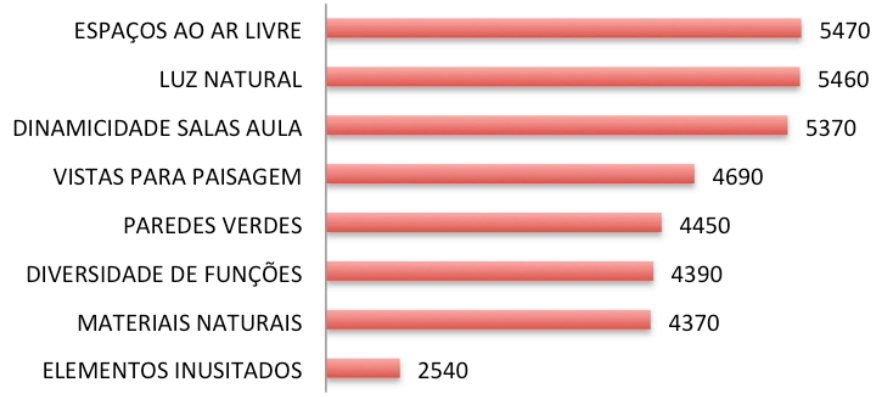

Figura 16 - Coeficiente de alfa de Cronbach aplicado para o questionário

\begin{tabular}{|c|c|c|c|c|c|c|c|c|c|c|c|c|c|}
\hline \multirow{2}{*}{\multicolumn{11}{|c|}{ ATRIBUTO 1}} & \multirow{2}{*}{\multicolumn{3}{|c|}{\begin{tabular}{|l|l|l|} 
SOMEDIA & VARISLNCIA \\
\end{tabular}}} \\
\hline & & & & & & & & \multicolumn{3}{|c|}{ Turma 10} & & & \\
\hline Satisfaçăo & 2 & 7 & 7 & 6 & 7 & & 5 & 6 & 5 & 7 & 620 & 6,08 & \\
\hline Respeito & 4 & 6 & 7 & 7 & 5 & 7 & 5 & 6 & 6 & 5 & 589 & 5,77 & 1,44 \\
\hline Simpatia & 6 & 6 & 6 & 7 & 7 & 7 & 6 & 7 & 7 & 7 & 610 & 5,98 & 1,23 \\
\hline Alegria & 3 & 6 & 7 & 6 & 7 & 7 & 6 & 7 & 6 & 7 & 610 & 5,98 & 1,07 \\
\hline Orgulho & 5 & 5 & 5 & 7 & 5 & 7 & 6 & 6 & 5 & 5 & 573 & 5,62 & 1,66 \\
\hline Encantamento & 7 & 7 & 5 & 6 & 7 & 7 & 5 & 7 & 6 & 7 & 637 & 6,25 & 0,92 \\
\hline Relaxamento & 7 & 7 & 6 & 5 & 7 & 7 & 6 & 7 & 5 & 7 & 617 & 6,05 & 1,49 \\
\hline SOMA & 34 & 44 & 43 & 44 & 45 & 49 & 39 & 46 & 40 & 45 & \multirow{2}{*}{\multicolumn{3}{|c|}{$\begin{array}{l}\text { ALFA DE } \\
\text { CRONBACH }\end{array}$}} \\
\hline MÉDIA & 41,7 & 41,7 & 41,7 & 41,7 & 41,7 & 41,7 & 41,7 & 41,7 & 41,7 & 41,7 & & & \\
\hline VARLÂNCIA & 0,59 & 0,05 & 0,02 & 0,05 & 0,11 & 0,52 & 0,07 & 0,18 & 0,03 & 0,11 & \multicolumn{3}{|c|}{$\begin{array}{c}\text { CRONBACH } \\
0,81 \\
\end{array}$} \\
\hline \multicolumn{11}{|c|}{ ATRIBUTO 2 } & \multirow{2}{*}{\multicolumn{3}{|c|}{\begin{tabular}{|l|l|l|} 
SOMÉDIA & VARLLANCAA \\
\end{tabular}}} \\
\hline & & & & & Turme & & & & & & & & \\
\hline Satisfação & 5 & 7 & 7 & 5 & 7 & 7 & 6 & 7 & 6 & 7 & 631 & 6,19 & 1,18 \\
\hline Estimulo & & 5 & 6 & 5 & 7 & 7 & 5 & 7 & 5 & 7 & 601 & 5,89 & 1,54 \\
\hline Relaxamento & 7 & 6 & 5 & 4 & 7 & 7 & 6 & 7 & 6 & 7 & 624 & 6,12 & 1,67 \\
\hline Inspiração & 5 & 5 & 5 & 6 & 7 & 7 & 5 & 7 & 4 & 7 & 624 & 6,12 & 1,47 \\
\hline Encantamento & 6 & 6 & 5 & 6 & 7 & 7 & 6 & 7 & 6 & 7 & 626 & 6,14 & 1.33 \\
\hline Respeito & 2 & 6 & 5 & 6 & 5 & 7 & 6 & 5 & 4 & 5 & 567 & 5,56 & 1.58 \\
\hline Simpatia & 3 & 5 & 6 & 6 & 7 & 7 & 5 & 7 & 5 & 5 & 593 & 5,81 & 1,34 \\
\hline Alegria & 7 & 5 & 7 & 6 & 7 & 7 & 6 & 7 & 6 & 5 & 625 & 6,13 & 1.02 \\
\hline SOMA & 42 & 45 & 46 & 44 & 54 & 56 & 45 & 54 & 42 & so & \multirow{2}{*}{\multicolumn{3}{|c|}{$\begin{array}{l}\text { ALFA DE } \\
\text { CRONBACH }\end{array}$}} \\
\hline MÉDIA & 48,0 & 48,0 & 48,0 & 48,0 & 48,0 & 48,0 & 48,0 & 48,0 & 48,0 & 48,0 & & & \\
\hline VARLL̈NCIA & 0.35 & 0.09 & 0.04 & 0,15 & 0.36 & 0,64 & 0.09 & 0.36 & 0.35 & 0.04 & \multicolumn{3}{|c|}{0,88} \\
\hline
\end{tabular}
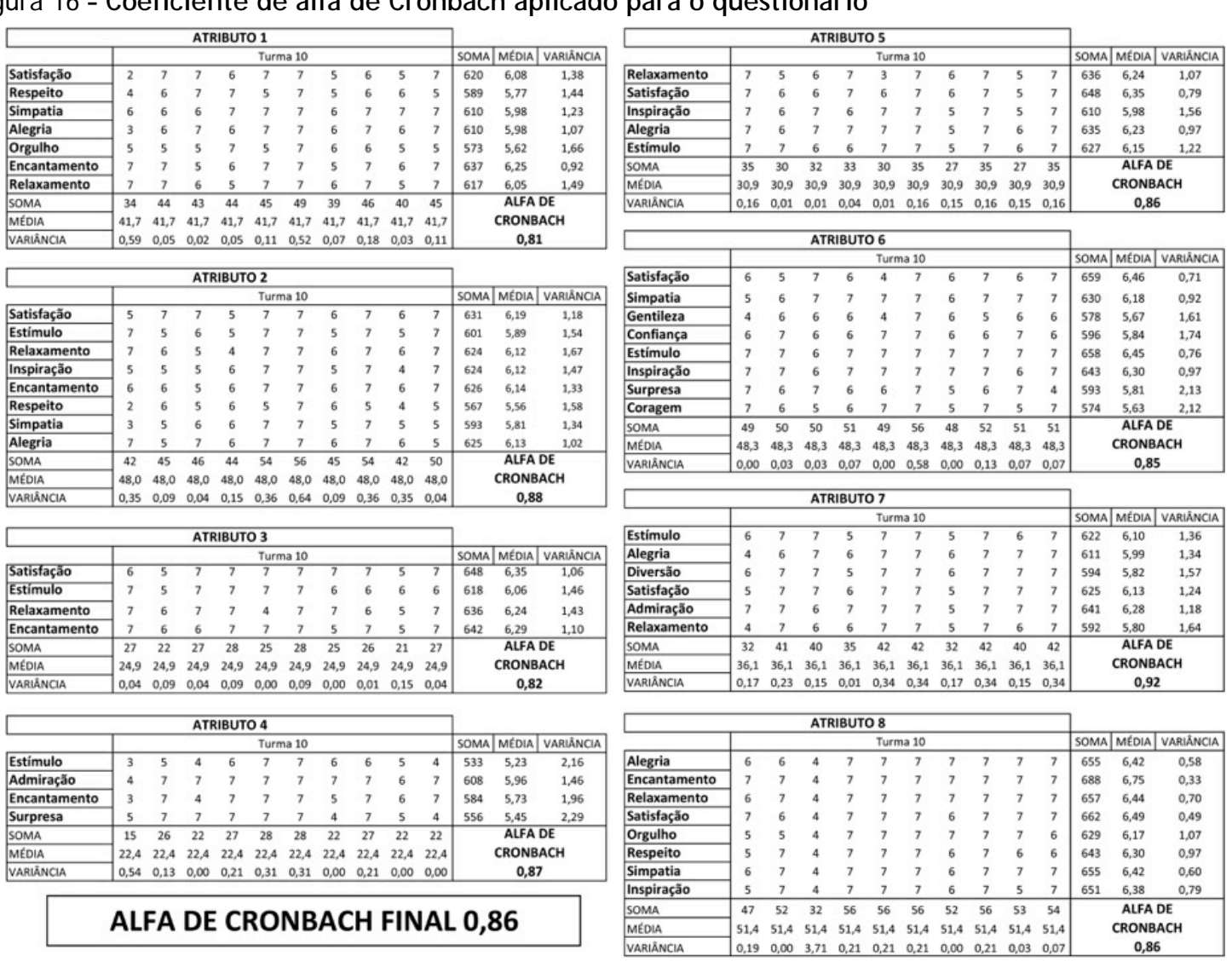

ALFA DE CRONBACH FINAL 0,86

Emoções positivas no uso do espaço construído de um campus universitário associadas aos atributos do design 51 
Outra contribuição relevante está na apresentação de diferentes atributos do design biofílico aplicados a um estudo de caso em arquitetura, o que amplia o repertório para inspirar futuros projetistas em como abordar o design biofílico e aplicar seus atributos em edificações. Por fim, o maior benefício resultante é a associação desses atributos biofílicos com as emoções positivas. É, portanto, uma contribuição para o projeto e avaliação do ambiente construído com foco na agradabilidade e bem-estar dos usuários.

Como sugestões futuras, a pesquisa pode ser complementada com levantamento de maior número de dados, aplicada com diferentes tipos de usuários, em diferentes momentos e em diferentes locais dentro da mesma edificação. Outra sugestão de trabalho futuro é a realização de semelhante estudo e avaliação em outras universidades ou locais de estudo, bem como em outras edificações que se propõem a aplicar os atributos do design biofílico para qualificação da experiência do usuário.

\section{Referências}

ALMEIDA, D.; SANTOS, M. A. R.; COSTA, A. F. Aplicação do Coeficiente Alfa de Cronbach nos Resultados de Um Questionário Para Avaliação de Desempenho da Saúde Pública. In: ENCONTRO NACIONAL DE ENGENHARIA DE PRODUÇÃO, São Carlos, 2010. Anais... São Carlos, 2010.

BROWNING, B.; COOPER, S. C. Human Spaces: the global impact of biophilic design in the workplace. Disponível em:

$<$ https://greenplantsforgreenbuildings.org/wpcontent/uploads/2015/08/Human-Spaces-ReportBiophilic-Global_Impact_Biophilic_Design.pdf > Acesso em: 6 jul. 2017.

CORTINA, J. M. What Is Coefficient Alpha? An examination of theory and applications. Journal of Applied Psychology, v. 78, p. 98-104, 1993.

DESMET, P. M. A. Faces of Product Pleasure: 25 positive emotions in human-product interactions. International Journal of Design, v. 6, n. 2, p. 129, 2012.

FREDRICKSON, B.; TUGADE, M.; WAUGH, C. What Good Are Positive in Crises? Journal of personality and Social Psychology, v. 84, n. 2, p. 365-376, 2003.

GIL, A. C. Como Elaborar Projetos de Pesquisa. São Paulo: Atlas, 1991.

JOHN, N.; REIS, A. T. Percepção, Estética e Uso do Mobiliário Urbano. Gestão \& Tecnologia, v. 5, p. 180-206, 2010.
JOYE, Y. Architectural Lessons from Environmental Psychology: the case of Biophilic Architecture. Review os General Psychology, v. 11, n. 4, p. 305-328, 2007.

KAPLAN, R. The Role of Nature in the Context of the Workplace. Landscape and Urban Planning, v. 26, p. 193-201, 1993.

KAPLAN, S.; KAPLAN, R. The Experience of Nature: a psychological perspective. New York: Cambridge University Press, 1989.

KELLERT, S.; CALABRESE, E. The Practice of Biophilic Design. Disponível em:

$<$ https://docs.wixstatic.com/ugd/21459d_81ccb84c af6d4bee8195f9b5af92d8f4.pdf>. Acesso em: 8 jul. 2017.

KHALID, H.; HELANDER, M. Customer Emotional Needs in Product Design. Concurrent Engineering: Research Applications, v. 14, n. 3, p. 197-205, 2006.

KÜLLER, R. Architecture and Emotions. In: MIKELLIDES, B. Architecture for People. New York: Holt, Rinehart \& Winston, 1980.

MONTEOLIVA, J. M.; PATTINI, A. Iluminación Natural en Aulas: analisis predictivo dinámico del rendimiento lumínico-energetico en clima soleados. Ambiente Construído, Porto Alegre, v. 13, n. 4, p. 235-248, out./dez. 2013.

MOURTHÉ, C. Mobiliário Urbano. Rio de Janeiro: 2AB, 1998.

NASSAR, J. Urban Design Aesthetics: the evaluative qualities of building exteriors.

Environmental Behavior, v. 26, p. 377-401, 1994.

NORMAN, D. Design Emocional. Rio de Janeiro: Rocco, 2008.

OCHOA, J.; ARAÚJO, D.; SATTLER, M. Análise do Conforto Ambiental em Salas de Aula: comparação entre dados técnicos e a percepção do usuário. Ambiente Construído, Porto Alegre, v. 12, n. 1, p. 91-114, jan./mar. 2012.

ORNSTEIN, S. W. Avaliação Pós-Ocupação (APO) do Ambiente Construído. São Paulo: Studio Nobel/EDUSP, 1992.

PIZZATO, G. Z. A., Design e Emoção na Utilização do Mobiliário Urbano em Espaços Públicos. Porto Alegre: Universidade Federal do Rio Grande do Sul, 2013.

REEVE, A. et al. Informing Healthy Building Design With Biophilic Urbanism Design Principles: a review and synthesis of current knowledge and research. Australia, 2012. 
REIS, A. T. da L.; LAY, M. C. D. Análise Quantitativa da Área de Estudos AmbienteComportamento. Ambiente Construído, Porto Alegre, v. 5, n. 2, p. 21-36, 2005.

REIS, A. T. da L.; LAY, M. C. D. Avaliação da Qualidade de Projetos: uma abordagem perceptiva e cognitiva. Ambiente Construído, Porto Alegre, v. 6, n. 3, p. 21-34, 2006.

RUSSEL, J. A.; MEHRABIAN, A. Evidence for a Three-Factor Theory of Emotions. Journal of Research in Personality, v. 11, p. 273-294, 1977.

SOUZA, C. O. O Espaço e a Sensibilidade dos Cidadãos. Arqtexto, v. 3, p. 72-83, 2003.

STREINER, D. L. Being Inconsistent About Consistency: when coefficient alpha does and doesn't matter. Journal of Personality

Assessment, v. 80, p. 217-222, 2003.
VALESAN, M.; FEDRIZZI, B.; SATTLER, M. Vantagens e Desvantagens da Utilização de PelesVerdes em Edificações Residenciais em Porto Alegre Segundo Seus Moradores. Ambiente Construído, Porto Alegre, v. 10, n. 3, p. 55-67, 2010.

WILSON, E. O. Biophilia: the human bond with other species. Cambridge: Harvard University Press, 1984.

\section{Agradecimentos}

Agradecimento especial para a instituição de ensino Unisinos, a qual disponibilizou o espaço físico para a aplicação dos questionários, sem a qual a realização desta pesquisa não teria sido possível. Agradecimento também à disponibilidade e atenção do corpo docente do curso de arquitetura e urbanismo da mesma instituição, que nos oportunizou o contato direto com os alunos em sala de aula e estimulou a aplicação do questionário.

\section{Flora Bittencourt Detanico}

Programa de Pós-Graduação em Design | Universidade Federal do Rio Grande do Sul | Rua Osvaldo Aranha, 99, Sala 408 | Porto Alegre RS - Brasil | CEP 90035-190 | Tel.: (51) 3308-4258 | E-mail: floradetanico@me.com

\section{Felipe André Schwab}

Programa de Pós-Graduação em Design | Universidade Federal do Rio Grande do Sul | Tel: (51) 99545-4667| E-mail: felipe.schwab@hotmail.com

\section{Gabriela Zubaran de Azevedo Pizzato}

Programa de Pós-Graduação em Design | Universidade Federal do Rio Grande do Sul | Tel.: (51) 3308-4262 Ramal 4262 | E-mail: gabrielapizzato@gmail.com

\section{Fabio Gonçalves Teixeira}

Programa de Pós-Graduação em Design | Universidade Federal do Rio Grande do Sul | Tel.: (51) 3308-4258 | E-mail: fabiogt@ufrgs.br

J ocelise J acques de J acques

Programa de Pós-Graduação em Design | Universidade Federal do Rio Grande do Sul | Tel.: (51) 3308-3125 | E-mail: jocelisej @gmail.com

\section{Branca Freitas de Oliveira}

Programa de Pós-Graduação em Design | Universidade Federal do Rio Grande do Sul | Tel.: (51) 3316-4258 | E-mail: branca@ufrgs.br

Revista Ambiente Construído

Associação Nacional de Tecnologia do Ambiente Construído

Av. Osvaldo Aranha, 99 - 3o andar, Centro

Porto Alegre - RS - Brasil CEP $90035-190$

Telefone: +55 (51) 3308-4084

Fax: +55 (51) 3308-4054

www. seer. ufrgs. br/ ambienteconstruido

E-mail: ambienteconstruido@ufrgs.br

\section{(i)}

This is an open-access article distributed under the terms of the Creative Commons Attribution License. 